\title{
Trends in United States neurosurgery residency education and training over the last decade (2009-2019)
}

\author{
Kurt A. Yaeger, MD, ${ }^{1}$ Stephan A. Munich, MD, ${ }^{2}$ Richard W. Byrne, MD, ${ }^{2}$ and \\ Isabelle M. Germano, MD, MBA ${ }^{1}$ \\ 'Department of Neurological Surgery, Icahn School of Medicine at Mount Sinai Hospital, New York, New York; and 'Department \\ of Neurological Surgery, Rush Medical College, Chicago, Illinois
}

\begin{abstract}
OBJECTIVE Postgraduate training in medicine has been under scrutiny in the last 10 years, with a focus on improving residents' education. The aim of this study was to quantify trends in neurosurgery residency (NSR) training and education over the last 10 years.

METHODS The authors assessed Accreditation Council for Graduate Medical Education (ACGME), National Resident Matching Program, and American Board of Neurological Surgeons records and searched PubMed to collate 2009-2019 data. Analyzed trends included residents' demographic data, programs' characteristics, graduation and attrition rates, match data, resident case logs, and qualitative educational curriculum changes.
\end{abstract}

RESULTS Significant increases in residents' demographic data $(p<0.05)$ included the number of female residents (from $12.7 \%$ to $17.6 \%$ ) and the absolute number of residents (from 1112 to 1462). Age (mean 28.8 years), ethnicity, and number of residents per program (mean 13 residents per program) were unchanged. There were 16 new ACGME NSR programs, with currently 115 programs nationwide. The number of applicants per year (324 applicants per year) and the matching rate (mean $64 \%$ ) remained stable. The mean attrition rate of $2.6 \%$ (range $2 \%-4 \%$ ) was higher than the mean 2.1\% ACGME attrition rate, a rate that decreased from 3\% in 2009 to $1.6 \%$ in 2019. Education curriculum changes aimed at the standardization of training across the US included residents' boot camp (2009), the Milestones project (2012), and mandatory 7-year training initiated in 2013. An increase in endovascular, functional, trauma, and spine resident caseload was noted. The number of yearly publications about US NSR education has significantly increased $(p<0.05)$.

CONCLUSIONS NSR education has received greater attention over the last decade in the US. Standardization of training has been implemented. A steady number of students remain interested in neurosurgery, with an increased number of women entering the field. Attention to wellness, in addition to high-quality education, should be further assessed as a factor to improve the overall NSR training and retention rate.

https://thejns.org/doi/abs/10.3171/2019.12.FOCUS19827

KEYWORDS neurosurgical residency; neurosurgery education; United States

$\mathrm{S}$ INCE residency training for neurological surgery in the US was formalized with the initiation of the Residency Review Committee (RRC) in 1953, educational paradigms and training philosophies have shifted substantially. ${ }^{26}$ What began as an offshoot from the American College of Surgeons (ACS) has branched into a highly complex and specialized training system, with both internal and external regulation, from the American Board of Neurological Surgeons (ABNS) and Accreditation Council for Graduate Medical Education (ACGME), respectively. The beginning of the past decade marked a turning point in neurosurgery training, with an enhanced focus on duty hour adherence, trainee wellness, and educational sanctity. However, to date, there have been no studies assessing the demographic and educational changes in US neurosurgery residency (NSR) over the last 10 years.

In July 2003, the ACGME issued a strict mandate of less than 80 hours worked per week, no more than 24 hours worked per shift, and 1 day without patient care responsibilities per week for all US residents. ${ }^{29}$ Given the high complexity of neurological surgery, its residency training has required innovative adaptations in order to balance resident fatigue and burnout with adequate clinical and operative education,,$^{30}$ especially given the considerable

ABBREVIATIONS ABNS = American Board of Neurological Surgeons; ACGME = Accreditation Council for Graduate Medical Education; NSR = neurosurgery residency. SUBMITTED October 30, 2019. ACCEPTED December 24, 2019.

INCLUDE WHEN CITING DOI: 10.3171/2019.12.FOCUS19827. 
concern from both residents and faculty on the perceived detriment of duty hours on NSR training. ${ }^{28}$

In the years that followed, many changes were enacted at the national level to standardize and promote education and wellness for neurosurgery residents. Until now, the effect of these changes on resident demographics, residency match statistics, and resident case log reports has not been clear. In this study, we present the quantitative and qualitative changes in US neurosurgery training programs and for residents within the last decade (2009-2019).

\section{Methods}

\section{NSR Program Trends}

NSR program changes in the US were assessed by reviewing the annual ACGME Data Resource Books. ${ }^{3-15}$ For the present study, all data from academic years 20092010 through 2018-2019 were reviewed. The following trends were analyzed: residents' demographics, medical school types, programs' characteristics (including number of programs, total number of residents, residents per program), absolute number of residents, graduating number of residents, attrition rate, and number of programs and their geographical location.

\section{Residents' Demographics, Graduation and Attrition Rate}

Age, sex, ethnicity, medical school type, and graduation and attrition rate data were analyzed. Data were obtained from the annual ACGME Data Resource Books. The attrition rate was calculated as the number of residents not continuing residency each year divided by the total number of residents each year.

\section{Programs' Characteristics}

The total number of programs, new programs and their geographical location, total and relative number of residents, and number of core faculty per program were analyzed. Data were obtained from the ACGME annual Data Resource Books. Per the ACGME, ${ }^{2}$ core faculty are defined as "All physician faculty members in a specialty program who have a significant role in the education of resident/fellows and who have documented qualifications to instruct and supervise. Core faculty members devote at least 15 hours per week to resident education and administration."

\section{Neurosurgery Match Results}

Data from the US residency match were obtained the National Resident Matching Program (NRMP) website..$^{32-42}$ Annual reports analyzed for this study included Main Residency Match Results, Applicant Surveys, Program Director Surveys, and Charting Outcomes in the Match reports. Information on the US neurosurgery program application and match process is elsewhere reported..$^{43}$

\section{Neurosurgery Resident Case Log Trends}

To analyze trends in neurosurgery resident surgical exposure, ACGME case log reports were analyzed from academic year 2009-2010 to 2017-2018. Archived ACGME national case log reports can be viewed and downloaded from the ACGME website. ${ }^{13-22}$ To assess overall changes in case log volume, several index cases were chosen to trend over the 10-year period. These index cases were arbitrarily chosen to represent a broad swath of neurosurgical expertise, ranging in complexity, specialty, and relative volume.

\section{Curriculum and Qualitative Changes}

Nationwide initiatives and protocols applied to the NSR curriculum between 2009 and 2019 were assessed and included residency duration, hands-on boot camp training, and the Milestones project. Qualitative changes to NSR standards were obtained by searching the ACGME and ABNS websites, as well as by a corresponding literature search in PubMed.

\section{NSR Literature Search}

A PubMed search using the MeSH terms "Neurosurgery," "Residency," and "United States" was carried out to determine the academic interest in NSR. The number of publications per year was assessed between 2009 and 2018.

\section{Statistical Analysis}

Descriptive statistics are reported either as the total number of events with valid percentage, or as an average. ANOVA with Fisher's exact test was used to analyze raw data over the years. A p value $<0.05$ was considered significant. Data were analyzed using commercially available Excel software. Trends were graphically shown, according to the following formula: trend $=($ known_y's, [known_x's], [new_x's], [const]).

\section{Results}

\section{Residents' Demographics and Programs' Characteristics}

Residents' demographics and programs' characteristics are summarized in Table 1.

Over the last decade, there was a significant increase in female residents from $12.7 \%$ of the overall population to $17.6 \%$ ( $\mathrm{p}<05$ ). Age (mean 28.8 years) and ethnicity remained unchanged: $49 \%$ Caucasian, $15 \%$ Asian, $4.4 \%$ African American, 4.1\% Hispanic, 0.2\% Native Americans, and $26.3 \%$ other/unknown in 2019. There was a significant increase (24\%) in the absolute number of residents with a current total of $1462(\mathrm{p}<0.05)$. During the same period, the US population sustained a 7\% growth from 307 million to 330 million (https://data.worldbank.org/ country/united-states). The number of residents per program did not significantly increase, with a current mean of 13 residents per program. There were 16 new ACGME programs, and 1 program lost accreditation, with a current total of 115 from 100 in 2009. The geographical distribution of the 16 new programs by US region was Northeast 6; Southeast 4; Northwest 4; and Southwest 2. The Southwest US region lost 1 program during the period, for a net gain of 1 NSRP. No programs were added in the South or West regions. A significant increase in neurosurgery core faculty was observed, with a current program mean of 17.5 up from 5.6. 
TABLE 1. Resident demographic data and NSR program characteristics

\begin{tabular}{|c|c|c|c|c|c|c|c|c|c|c|c|}
\hline \multirow[b]{2}{*}{ Variable } & \multicolumn{10}{|c|}{ Academic Year } & \multirow[b]{2}{*}{ Mean } \\
\hline & 2009 & 2010 & 2011 & 2012 & 2013 & 2014 & 2015 & 2016 & 2017 & 2018 & \\
\hline \multicolumn{12}{|l|}{ Demographics } \\
\hline Age (mean yrs) & 28.8 & 28.7 & 28.7 & 28.8 & 28.5 & 28.9 & 9.1 & 28.6 & 28.9 & 29.3 & 28.8 \\
\hline Women (\%) & 12.7 & 14.3 & 15.1 & 16.2 & 16.2 & 17.3 & 17 & 17.4 & 17.6 & 17.3 & 16.11 \\
\hline \multicolumn{12}{|l|}{ Ethnicity (\%) } \\
\hline White & & & 50.5 & 49.4 & 42.1 & 49.9 & 49.8 & 50.0 & 50.8 & 49.9 & 49.1 \\
\hline Asian & & & 14.5 & 15.4 & 15.0 & 15.3 & 15.5 & 15.3 & 14.1 & 14.4 & 14.9 \\
\hline Hispanic & & & 4.2 & 4.5 & 4.2 & 4.3 & 3.8 & 3.8 & 3.6 & 4.2 & 4.1 \\
\hline Black & & & 4.5 & 4.5 & 4.6 & 4.6 & 4.5 & 4.4 & 4.2 & 4.0 & 4.4 \\
\hline Native & & & 0.3 & 0.2 & 0.2 & 0.2 & 0.2 & 0.2 & 0.2 & 0.1 & 0.2 \\
\hline Other & & & 9.3 & 8.2 & 8.5 & 8.3 & 7.8 & 7.1 & 7.0 & 7.2 & 7.9 \\
\hline Unknown & & & 16.7 & 17.7 & 17.5 & 17.5 & 18.3 & 19.2 & 20.0 & 20.2 & 18.4 \\
\hline \multicolumn{12}{|l|}{ MS type (\%) } \\
\hline US allopathic & 88.2 & 88.1 & 88.6 & 89.7 & 90.3 & 90.7 & 91.4 & 90.8 & 90.1 & 87.9 & 89.6 \\
\hline US osteopathic & 0.4 & 0.4 & 0.4 & 0.5 & 0.5 & 0.6 & 0.6 & 1.6 & 1.8 & 4.4 & 1.1 \\
\hline International & 11.3 & 11.4 & 10.9 & 9.8 & 9.2 & 8.6 & 7.9 & 7.5 & 8.0 & 7.5 & 9.2 \\
\hline Canadian & 0.1 & 0.1 & 0.1 & 0 & 0 & 0 & 0.1 & 0.1 & 0.1 & 0.1 & 0.1 \\
\hline \multicolumn{12}{|l|}{ Program characteristics } \\
\hline Programs (no.) & 100 & 101 & 101 & 102 & 105 & 105 & 108 & 110 & 112 & 115 & 106 \\
\hline NS resident (no.) & 1112 & 1133 & 1179 & 1212 & 1265 & 1295 & 1325 & 1375 & 1408 & 1462 & 1277 \\
\hline $\mathrm{R} / \mathrm{P}$ (mean) & 11.1 & 11.2 & 11.7 & 11.9 & 12.0 & 12.3 & 12.3 & 12.5 & 12.6 & 12.7 & 12.0 \\
\hline Faculty (mean) & - & - & 5.6 & 12 & 11.4 & 11.5 & 15.8 & 16.5 & 17 & 17.5 & 13.4 \\
\hline
\end{tabular}

MS = medical student; $N S$ = neurosurgery; $R / P=$ residents per program.

Each academic year indicates the beginning of the year, for example, $2009=2009-2010$.

\section{Resident Graduation and Attrition Rates}

The yearly number of graduating neurosurgery residents remained stable over the years (Table 2). The attrition rate ranged from $2 \%$ in 2018-2019 to 4\% in 2010-2011, with a mean of $2.6 \%$. This rate remains higher than the mean ACGME rate of $2.1 \%$, a rate decrease from $3 \%$ in 2009 to $1.6 \%$ in 2019 (Table 2). The most common reasons for not completing NSR were withdrawal and transfer, with dismissal making up a minority of cases each year.

\section{Neurosurgery Match Trends}

Table 3 summarizes the neurosurgery match trends. The number of unfilled positions per year remained stable with a mean of 1.3 (range 0-3). Of all applicants for NSR, on average $72 \%$ were US graduating senior allopathic medical students. Of each matched class, US se- niors made up on average $91 \%$, whereas non-US international medical school graduates made up $4.5 \%$. The mean match rate for all applicants was $64 \%$ and was $80 \%$ for US seniors.

\section{Resident Case Log Trends}

Neurosurgery resident case log trends are summarized in Table 4 and Fig. 1. In 2012-2013, there was a marked increase in the number of cases logged across subspecialties. This sudden increase in case volume is likely a reflection of the introduction of the Milestones program, with its associated emphasis on tracking case volume, as well as proficiency. Since that time, the mean number of cases per resident has remained relatively stable for the following: craniotomy for aneurysms, craniotomy for brain tumors, carotid endarterectomy, and peripheral nerve. The mean

TABLE 2. Neurosurgery residents' graduation and attrition rates

\begin{tabular}{lrrrrrrrrrrr}
\hline & \multicolumn{10}{c}{ Academic Year } \\
\cline { 2 - 12 } \multicolumn{1}{c}{ Variable } & 2009 & 2010 & 2011 & 2012 & 2013 & 2014 & 2015 & 2016 & 2017 & 2018 & Mean \\
\hline Graduation rate (\%) & 13.8 & 14.1 & 13.2 & 11.9 & 14.1 & 12.3 & 12.8 & 13.8 & 13.4 & 13.1 & 13.3 \\
\hline NS attrition rate (\%) & 3.0 & 4.1 & 3.0 & 2.6 & 2.1 & 1.9 & 3.0 & 2.3 & 2.4 & 2.0 & 2.6 \\
\hline ACGME attrition rate (\%) & 3.0 & 2.3 & 2.4 & 2.4 & 2.0 & 1.8 & 1.8 & 1.7 & 1.6 & 1.6 & 2.1 \\
\hline
\end{tabular}


TABLE 3. Neurosurgery match data

\begin{tabular}{|c|c|c|c|c|c|c|c|c|c|c|c|c|}
\hline \multirow[b]{2}{*}{ Variable } & \multicolumn{11}{|c|}{ Match Year } & \multirow[b]{2}{*}{ Mean } \\
\hline & 2009 & 2010 & 2011 & 2012 & 2013 & 2014 & 2015 & 2016 & 2017 & 2018 & 2019 & \\
\hline Programs (no.) & 97 & 97 & 98 & 98 & 99 & 102 & 102 & 105 & 107 & 110 & 112 & 102 \\
\hline Positions (no.) & 191 & 191 & 195 & 196 & 204 & 206 & 210 & 216 & 218 & 225 & 232 & 208 \\
\hline Unfilled (no.) & 0 & 3 & 3 & 2 & 1 & 0 & 2 & 2 & 0 & 0 & 1 & 1.3 \\
\hline \multicolumn{13}{|l|}{ Applicants } \\
\hline Total (no.) & 317 & 309 & 283 & 318 & 314 & 335 & 354 & 354 & 311 & 325 & 341 & 324 \\
\hline US MD (\%) & 69.7 & 68.3 & 73.5 & 63.8 & 76.8 & 72.5 & 72.3 & 74.5 & 68.2 & 73.8 & 77.7 & 72.0 \\
\hline \multicolumn{13}{|l|}{ Match rates } \\
\hline Overall (\%) & 60.3 & 60.8 & 67.8 & 61.0 & 64.6 & 61.5 & 58.8 & 60.5 & 70.1 & 69.2 & 67.7 & 63.8 \\
\hline US MD (\%) & 77.8 & 82.0 & 84.1 & 83.7 & 78.8 & 77.8 & 73.4 & 86.3 & 84.6 & 84.6 & 80.4 & 80.3 \\
\hline
\end{tabular}

US MD = US allopathic medical students.

number of cases per resident has increased for the following: endovascular aneurysm treatment, functional, trauma, total spine, arteriography, and ventriculostomy. The number of total pediatric cases decreased overall during the time period.

\section{Curriculum and Qualitative Changes \\ Boot Camp (2009)}

In 2009, the Society of Neurological Surgeons began a national simulation course at 6 sites representing the 6 geographical US regions (Northeast, Southeast, West, South, Northwest, and Southwest) created to address the shift of the internship year in neurosurgery from under general surgery to neurosurgical departments. The effort was put forth in order to ensure that interns had the proper training to manage both the professional and the technical aspects of their roles on a clinical neurosurgery service. The course initially was lecture and simulation based, but based on resident feedback, the course shifted to a "flipped classroom" model, with online prestudy followed by small group interactive discussion with senior faculty. Nearuniversal attendance by all residents in the US has been consistently seen since the course began. ${ }^{47}$ The Society of Neurological Surgeons added a junior resident simulation course at 3 sites in 2013. This course was created to educate rising junior residents on the next level of clinical service management, leadership, and surgical skills. Over 90\% of US residents have attended this course, which also used the flipped classroom model.

\section{Milestones Program (2012)}

The ACGME Milestones project changed the organizational structure of neurosurgical residency to be based on the level achieved rather than the prior marker of time. ${ }^{31}$ Progression through Milestones-based training is designed to make medical education more explicit, intentional, and trackable. This change was intended to make the desired goals of training transparent and to give both the resident and the educators clear language for discussing a resident's progress or lack of progress. The progression through Milestones levels 1-5 should parallel, but does not have to clearly track, the progression in years of the residency, as program structures differ. Reaching level 4 of the Milestones should be a graduation goal but is not a requirement. Level 5 Milestones are fellowship-level goals but may be attained by senior residents.

\section{7-Year Residency Duration (2014)}

Prior to 2013, approximately $20 \%$ of programs had 6 -year residency requirements, with the remaining $80 \%$ having a 7-year minimum requirement. In 2014, all neurosurgery programs had a 7-year length, after an ABNS mandate required 84 months of postgraduate residency training.

\section{Neurosurgery Education Literature Trends}

Results from a PubMed longitudinal search indicated a growing interest in neurosurgical education in the US from a research and policy perspective (Fig. 2). The search yielded 190 publications within the study period, with 11 published in 2009 and 31 published in 2018, representing a $181 \%$ increase.

\section{Discussion}

Educating the next generation of neurosurgeons is essential for the health and safety of our patients. Analyzing the trends of our education system allows quantification of the implemented changes and the seeking out of new directions for improvement. Our current study showed a steady number of young doctors interested in neurosurgery, with an increased number of women entering the workforce. The attrition rate of both men and women, however, is higher than that of the average ACGME residency. This raises the opportunity to further investigate the possible factors contributing to it and to implement changes to improve this rate. Finally, over the last decade, the need for curricular standardization in the US was recognized and steps were taken toward improvement, including the implementation of boot camps, the introduction of competency-based trackable education (the Milestones project), and the initiation of a mandatory 7-year training process. The increased interest in improving US NSR education is 


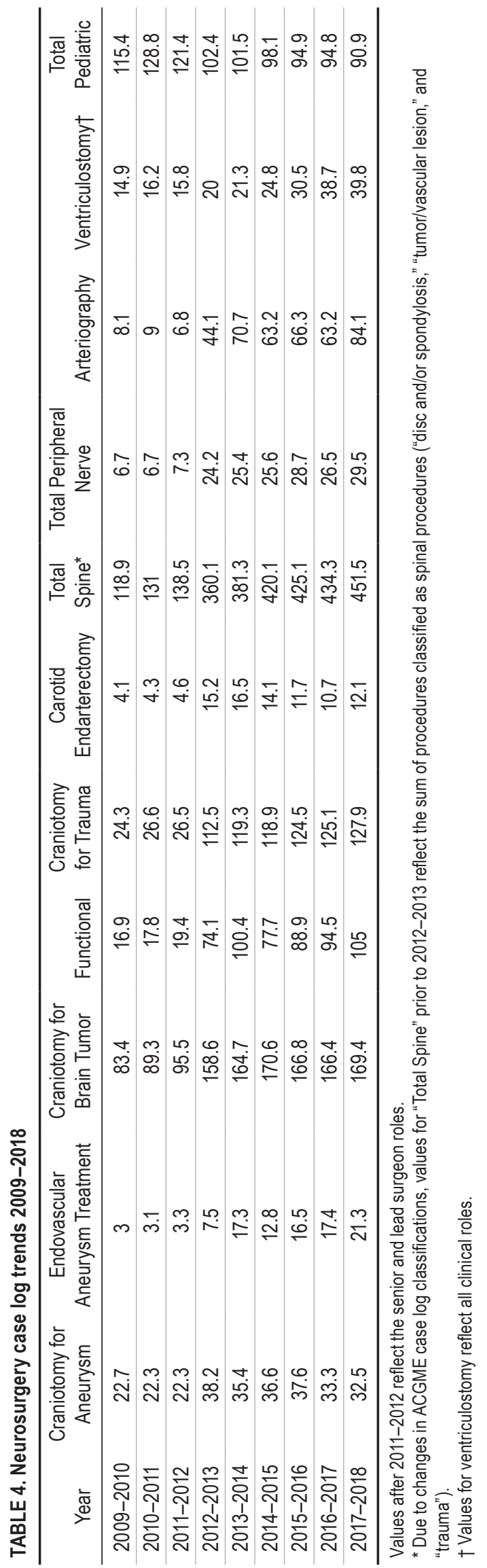

also corroborated by a significant increase in the number of published papers on this topic.

Neurological surgery is one of the most competitive and demanding specializations in medicine. Our study found that over the last decade, neurological surgery continued to attract a steady number of medical students, with an unchanged matching rate. This is reassuring, as previous studies had suggested that our field was losing ground to other less demanding specialties. ${ }^{24}$ Demographic changes for medical students began over 2 decades ago when the proportion of women grew substantially, eventually overtaking men in number or matriculates in 2017. ${ }^{1}$ The disproportionate trend in the recruitment and retention of women in neurosurgery has been recognized, despite women representing a growing cohort of neurosurgery residents..$^{25,44}$ Strategies to recruit a diverse workforce have been published ${ }^{25}$ and should be the focus of additional studies. Our study corroborates such growth. As previously reported, it is important to ensure that this increase can translate into an overall increase in ABNS certification and professional career in neurosurgery. ${ }^{45}$

The increased number of neurosurgery residents trained over the last decade exceeds the increase in the US population: $24 \%$ versus $7 \%$, respectively. The need for a greater number of neurosurgeons might be justified by multiple factors, including increased population longevity, greater access to medical care, and improved diagnostic modalities, to mention a few. The shift noted in neurosurgery case log trends showing an increase in the number of cases in specific areas of neurosurgery, such us endovascular, spine, trauma, and functional neurosurgery, might support the above statement. Additional studies are necessary to ensure that the rate of newly trained neurosurgeons does not exceed the population's need.

Over the last 50 years, neurosurgical education/training has evolved from a sheer volume of exposure to one of structured curricula; it then proceeded to undergo scrutiny, with a major focus being placed on the physician's personal health and patient's safety, culminating in the 80-hour workweek restriction instituted by the ACGME. ${ }^{23}$ Subsequently, additional aspects of education/ training were deemed important, including standardization of curricula across the US, and these were achieved by implementing a measurable competency-based matrix, the Milestones program. ${ }^{31}$ With this change, there was no longer an assumption of mastery by year but an explicit tracking of agreed-upon Milestones, chosen by a representative body from organized educational neurosurgery, tracked by neurosurgery subspecialty and by ACGME competencies. Neurosurgery was one of the early subspecialties to transition into Milestones-based training. ${ }^{46}$ This was later updated and revised for Milestones 2.0, with the revised Milestones completed with updated ACGME competency-based Milestones. ${ }^{27}$

Differences in training across programs can create a problem in the heterogeneity of the workforce provided. This weakness was recognized over the last decade and efforts were made to improve standardization. To address the change in eliminating the first year of NSR as a general surgery year, the boot camp was created ${ }^{47}$ which resulted in standardization of technical skills and educa- 


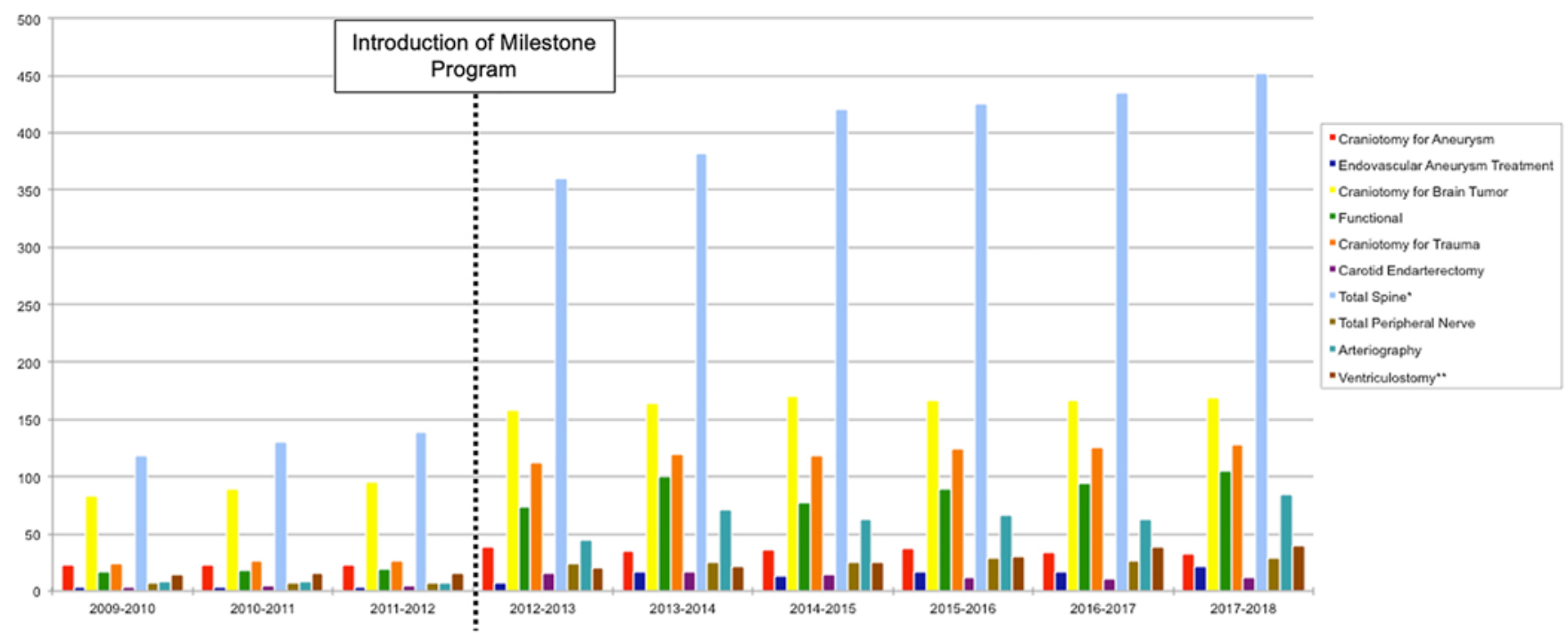

FIG. 1. Neurosurgery resident case log trends. Values after 2011-2012 reflect the senior and lead surgeon roles. Asterisk indicates that, due to changes in ACGME case log classifications, values for "Total Spine" prior to 2012-2013 reflect the sum of procedures classified as spinal procedures ("disc and/or spondylosis," "tumor/vascular lesion," and "trauma"). Double asterisk indicates that values for ventriculostomy reflect all clinical roles.

tional material across the US with a participation rate exceeding $90 \%$. Additional standardization of NSR training was accomplished by mandating a 7-year program across the US in $2014 .{ }^{23}$

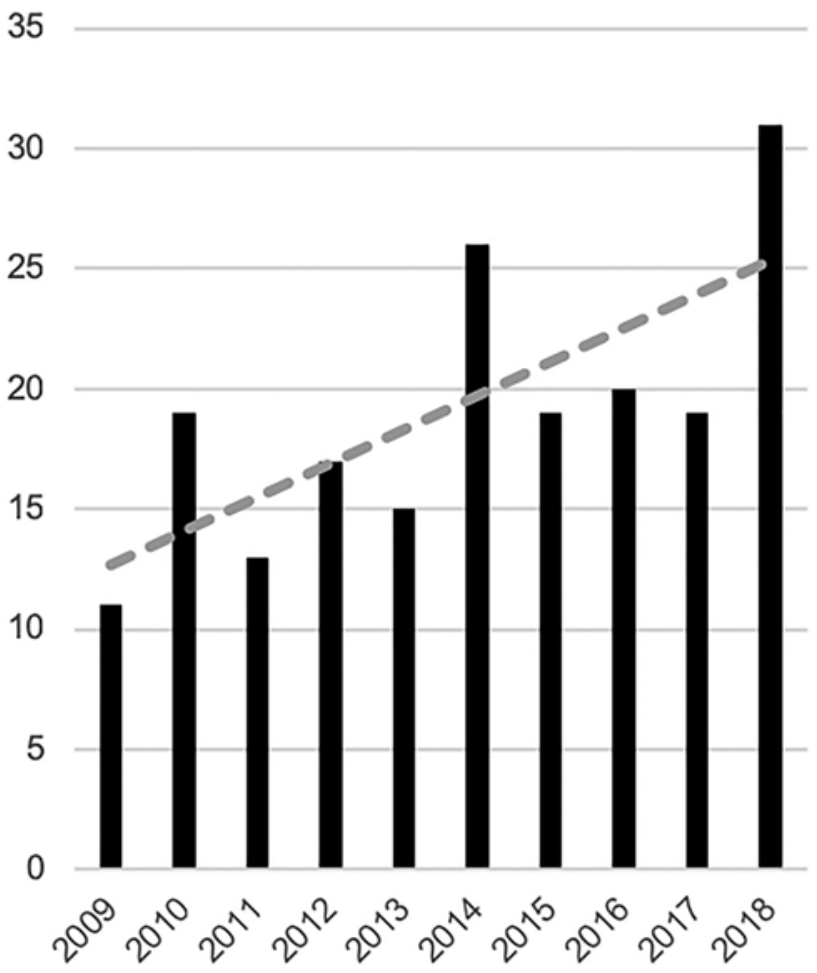

FIG. 2. Graph depicting the results of literature search of NSR publications in the US between 2009 and 2018, as described in Methods. The dashed line shows the trend over the last decade.

\section{Conclusions}

Over the last decade, NSR education and training gained in importance. Albeit demanding and competitive, our field continues to attract young doctors, and the workforce has seen an increase in the number of women. Tangible changes were implemented to ensure greater curricular standardization across the US and greater measurable, competence-based achievements. Further attention should be focused on retention and other factors that can positively affect the residents' training experience. We hope that our analysis will spark the interest of neurosurgeons practicing in other countries to examine their training trends. Comparing and contrasting the direction of international neurosurgery education and training will allow our field to update the needs of our trainees around the world and ultimately result in providing better care to our patients.

\section{References}

1. Association of American Medical Colleges: More Women Than Men Enrolled in U.S. Medical Schools in 2017.

Washington, DC: AAMC, 2017 (https://www.aamc.org/ news-insights/press-releases/more-women-men-enrolled-usmedical-schools-2017) [Accessed January 10, 2020]

2. Accreditation Council for Graduate Medical Education: Accreditation Council for Graduate Medical Education Glossary of Terms. Chicago: ACGME, 2018 (https:// www.acgme.org/Portals/0/PDFs/ab_ACGMEglossary.pdf) [Accessed January 10, 2020]

3. Accreditation Council for Graduate Medical Education: ACGME Data Resource Book 2009-2010. Chicago: ACGME, 2010 (https://www.acgme.org/About-Us/ Publications-and-Resources/Graduate-Medical-EducationData-Resource-Book) [Accessed January 10, 2020]

4. Accreditation Council for Graduate Medical Education: ACGME Data Resource Book 2010-2011. Chicago: ACGME, 2011 (https://www.acgme.org/About-Us/ Publications-and-Resources/Graduate-Medical-Education- 
Data-Resource-Book) [Accessed January 10, 2020]

5. Accreditation Council for Graduate Medical Education: ACGME Data Resource Book 2011-2012. Chicago: ACGME, 2012 (https://www.acgme.org/About-Us/ Publications-and-Resources/Graduate-Medical-EducationData-Resource-Book) [Accessed January 10, 2020]

6. Accreditation Council for Graduate Medical Education: ACGME Data Resource Book 2012-2013. Chicago: ACGME, 2013 (https://www.acgme.org/About-Us/ Publications-and-Resources/Graduate-Medical-EducationData-Resource-Book) [Accessed January 10, 2020]

7. Accreditation Council for Graduate Medical Education: ACGME Data Resource Book 2013-2014. Chicago: ACGME, 2014 (https://www.acgme.org/About-Us/ Publications-and-Resources/Graduate-Medical-EducationData-Resource-Book) [Accessed January 10, 2020]

8. Accreditation Council for Graduate Medical Education: ACGME Data Resource Book 2014-2015. Chicago: ACGME, 2015 (https://www.acgme.org/About-Us/ Publications-and-Resources/Graduate-Medical-EducationData-Resource-Book) [Accessed January 10, 2020]

9. Accreditation Council for Graduate Medical Education: ACGME Data Resource Book 2015-2016. Chicago: ACGME, 2016 (https://www.acgme.org/About-Us/ Publications-and-Resources/Graduate-Medical-EducationData-Resource-Book) [Accessed January 10, 2020]

10. Accreditation Council for Graduate Medical Education: ACGME Data Resource Book 2016-2017. Chicago: ACGME, 2017 (https://www.acgme.org/About-Us/ Publications-and-Resources/Graduate-Medical-EducationData-Resource-Book) [Accessed January 10, 2020]

11. Accreditation Council for Graduate Medical Education: ACGME Data Resource Book 2017-2018. Chicago: ACGME, 2018 (https://www.acgme.org/About-Us/ Publications-and-Resources/Graduate-Medical-EducationData-Resource-Book) [Accessed January 10, 2020]

12. Accreditation Council for Graduate Medical Education: ACGME Data Resource Book 2018-2019. Chicago: ACGME, 2019 (https://www.acgme.org/About-Us/ Publications-and-Resources/Graduate-Medical-EducationData-Resource-Book) [Accessed January 10, 2020]

13. Accreditation Council for Graduate Medical Education: ACGME National Data Report: Neurological Surgery Case Logs 2009-2010. Chicago: ACGME, 2010 (https:// www.acgme.org/Portals/0/PDFs/NSNatReports0910.pdf) [Accessed January 10, 2020]

14. Accreditation Council for Graduate Medical Education: ACGME National Data Report: Neurological Surgery Case Logs 2010-2011. Chicago: ACGME, 2011 (https:// www.acgme.org/Portals/0/PDFs/NSNatData1011.pdf) [Accessed January 10, 2020]

15. Accreditation Council for Graduate Medical Education: ACGME National Data Report: Neurological Surgery Case Logs 2011-2012. Chicago: ACGME, 2012 (https:// www.acgme.org/Portals/0/NSNatData1112.pdf) [Accessed January 10, 2020]

16. Accreditation Council for Graduate Medical Education: ACGME National Data Report: Neurological Surgery Case Logs 2012-2013. Chicago: ACGME, 2013 (https:// www.acgme.org/Portals/0/NSNatData1213.pdf) [Accessed January 10, 2020]

17. Accreditation Council for Graduate Medical Education: ACGME National Data Report: Neurological Surgery Case Logs 2013-2014. Chicago: ACGME, 2014 (https:// www.acgme.org/Portals/0/NeurologicalSurgery_National Report_Program_Version.pdf) [Accessed January 10, 2020]

18. Accreditation Council for Graduate Medical Education: ACGME National Data Report: Neurological Surgery Case Logs 2014-2015. Chicago: ACGME, 2015 (https://
www.acgme.org/Portals/0/PDFs/160_National_Report Program_Version.pdf) [Accessed January 10, 2020]

19. Accreditation Council for Graduate Medical Education: ACGME National Data Report: Neurological Surgery Case Logs 2015-2016. Chicago: ACGME, 2016 (https://www. acgme.org/Portals/0/PDFs/160_National_Report_Program_ Version_2015-2016.pdf) [Accessed January 10, 2020]

20. Accreditation Council for Graduate Medical Education: ACGME National Data Report: Neurological Surgery Case Logs 2016-2017. Chicago: ACGME, 2017 (https:// www.acgme.org/Portals/0/PDFs/160_National_Report_ Program_Version_2016-2017.pdf) [Accessed January 10, 2020]

21. Accreditation Council for Graduate Medical Education: ACGME National Data Report: Neurological Surgery Case Logs 2017-2018. Chicago: ACGME, 2018 (https:// www.acgme.org/Portals/0/PDFs/160_National_Report_ Program_Version_2017-2018.pdf) [Accessed January 10, 2020]

22. Accreditation Council for Graduate Medical Education: ACGME National Data Report: Neurological Surgery Case Logs 2018-2019. Chicago: ACGME, 2019 (https:// www.acgme.org/Portals/0/PDFs/160_National_Report_ Program_Version_2018-2019.pdf) [Accessed January 10, 2020]

23. Accreditation Council for Graduate Medical Education: Common Program Requirements. Chicago: ACGME (https://www.acgme.org/What-We-Do/Accreditation/ Common-Program-Requirements) [Accessed January 10, 2020]

24. Agarwal N, Norrmén-Smith IO, Tomei KL, Prestigiacomo CJ, Gandhi CD: Improving medical student recruitment into neurological surgery: a single institution's experience. World Neurosurg 80:745-750, 2013

25. Benzil DL, Abosch A, Germano I, Gilmer H, Maraire JN, Muraszko K, et al: The future of neurosurgery: a white paper on the recruitment and retention of women in neurosurgery. $\mathbf{J}$ Neurosurg 109:378-386, 2008

26. Clark K: Accreditation and approval of residency positions in neurological surgery in the United States: an overview. Neurosurgery 9:601-603, 1981

27. Conforti LN, Yaghmour NA, Hamstra SJ, Holmboe ES, Kennedy B, Liu JJ, et al: The effect and use of milestones in the assessment of neurological surgery residents and residency programs. J Surg Educ 75:147-155, 2018

28. Fargen KM, Chakraborty A, Friedman WA: Results of a national neurosurgery resident survey on duty hour regulations. Neurosurgery 69:1162-1170, 2011

29. Friedman WA: Resident duty hours in American neurosurgery. Neurosurgery 54:925-933, 2004

30. Grady MS, Batjer HH, Dacey RG: Resident duty hour regulation and patient safety: establishing a balance between concerns about resident fatigue and adequate training in neurosurgery. J Neurosurg 110:828-836, 2009

31. Nasca TJ, Philibert I, Brigham T, Flynn TC: The next GME accreditation system-rationale and benefits. N Engl J Med 366:1051-1056, 2012

32. National Resident Matching Program: Results and Data: 2009 Main Residency Match. Washington, DC: NRMP, 2009 (http://www.nrmp.org/report-archives/) [Accessed January 10, 2020]

33. National Resident Matching Program: Results and Data: 2010 Main Residency Match. Washington, DC: NRMP, 2010 (http://www.nrmp.org/report-archives/) [Accessed January 10, 2020]

34. National Resident Matching Program: Results and Data: 2011 Main Residency Match. Washington, DC: NRMP, 2011 (http://www.nrmp.org/report-archives/) [Accessed January 10, 2020] 
35. National Resident Matching Program: Results and Data: 2012 Main Residency Match. Washington, DC: NRMP, 2012 (http://www.nrmp.org/report-archives/) [Accessed January 10, 2020]

36. National Resident Matching Program: Results and Data: 2013 Main Residency Match. Washington, DC: NRMP, 2013 (http://www.nrmp.org/report-archives/) [Accessed January 10, 2020]

37. National Resident Matching Program: Results and Data: 2014 Main Residency Match. Washington, DC: NRMP, 2014 (http://www.nrmp.org/report-archives/) [Accessed January 10, 2020]

38. National Resident Matching Program: Results and Data: 2015 Main Residency Match. Washington, DC: NRMP, 2015 (http://www.nrmp.org/report-archives/) [Accessed January 10, 2020]

39. National Resident Matching Program: Results and Data: 2016 Main Residency Match. Washington, DC: NRMP, 2016 (http://www.nrmp.org/report-archives/) [Accessed January 10, 2020]

40. National Resident Matching Program: Results and Data: 2017 Main Residency Match. Washington, DC: NRMP, 2017 (http://www.nrmp.org/report-archives/) [Accessed January 10, 2020]

41. National Resident Matching Program: Results and Data: 2018 Main Residency Match. Washington, DC: NRMP, 2018 (http://www.nrmp.org/report-archives/) [Accessed January 10, 2020]

42. National Resident Matching Program: Results and Data: 2019 Main Residency Match. Washington, DC: NRMP, 2019 (http://www.nrmp.org/report-archives/) [Accessed January 10, 2020]

43. Neurosurgery Match: Resources for Neurosurgical Residency Application and Beyond. NeurosurgeryMatch.org (https:// neurosurgerymatch.org/) [Accessed January 10, 2020]
44. Renfrow JJ, Rodriguez A, Liu A, Pilitsis JG, Samadani U, Ganju A, et al: Positive trends in neurosurgery enrollment and attrition: analysis of the 2000-2009 female neurosurgery resident cohort. J Neurosurg 124:834-839, 2016

45. Renfrow JJ, Rodriguez A, Wilson TA, Germano IM, Abosch A, Wolfe SQ: Tracking career paths of women in neurosurgery. Neurosurgery 82:576-582, 2018

46. Selden NR, Abosch A, Byrne RW, Harbaugh RE, Krauss WE, Mapstone TB, et al: Neurological surgery milestones. J Grad Med Educ 5 (1 Suppl 1):24-35, 2013

47. Selden NR, Origitano TC, Burchiel KJ, Getch CC, Anderson VC, McCartney S, et al: A national fundamentals curriculum for neurosurgery PGY1 residents: the 2010 Society of Neurological Surgeons boot camp courses. Neurosurgery 70:971-981, 2012

\section{Disclosures}

Dr. Germano reports that she is a consultant for Brainlab and Integra and that she owns stock in Elminda.

\section{Author Contributions}

Conception and design: Germano, Byrne. Acquisition of data: Yaeger, Munich, Byrne. Analysis and interpretation of data: all authors. Drafting the article: Germano, Yaeger, Byrne. Critically revising the article: all authors. Reviewed submitted version of manuscript: all authors. Statistical analysis: Germano, Yaeger.

\section{Correspondence}

Isabelle M. Germano: Icahn School of Medicine at Mount Sinai, New York, NY. isabelle.germano@mountsinai.org. 